\title{
Inerter-Connected Double Tuned Mass Damper for Passive Control of Buildings under Seismic Excitation
}

\author{
Himan Hojat Jalali', Maziar Fahimi Farzam²* \\ ${ }^{1}$ Department of Civil Engineering, University of Texas at Arlington, 701 S. Nedderman Drive, Arlington, TX 76019, USA \\ 2 Faculty of Engineering, University of Maragheh, Daneshgah Boulevard, Madar Square, 83111-55181 Maragheh, Iran \\ * Corresponding author, e-mail: m.farzam@maragheh.ac.ir
}

Received: 04 December 2021, Accepted: 04 January 2022, Published online: 18 January 2022

\begin{abstract}
In current work the Inerter-Connected Double Tuned Mass Damper (ICDTMD) is employed for structural control of a well-recognized benchmark 10-story linear shear building. The ICDTMD is introduced to overcome the practical limitations of the roof-top tuned mass damper inerter (TMDI), in which the second terminal of the inerter is connected to the lower floors of the building. To this end, a modification of the double tuned mass damper (DTMD) with a linking inerter is proposed to not only exploit the promising features of inerter but also surmount the architectural interference of the effective TMDI configurations. The TMDs free parameters are optimized using particle swarm optimization algorithm (PSO) for two different single objective functions, i.e., the $\mathrm{H}_{\infty}$ norms of roof displacement and story drifts were minimized for robust tuning. To evaluate the robustness of the optimal damper, its performance was compared to a traditional roof-top single tuned mass damper (STMD) and DTMD in both frequency and time domains (time history analysis for four far- and near-field records) for different preselected mass and inertance ratios. The performance indices in the time domain were selected as the maximum story drifts, story acceleration and shear. Results show that the rooftop ICDTMD, unlike the rooftop TMDI, provides a similar level of response reduction as STMD, while being more reliable due to redundancy. In addition, the ICDTMD exhibits a similar level of response reduction as the DTMD with significantly smaller optimized spring stiffness.
\end{abstract}

Keywords

structural control, inerter, tuned mass damper, particle swarm optimization, time history analysis

\section{Introduction}

TMD and its modifications are one the most widely-studied and employed passive control devices to absorb the dynamic vibration of a variety of buildings [1], bridges [2], wind turbines [3], offshore platforms [4], high-rise chimneys [5], and transmission lines [6]. The promising features of TMD render it a hot topic for research [7] and a reliable device for practical applications [8] in the structural control community. However, to deploy TMDs for seismic vibration control, the main shortcomings of TMDs, i.e., narrowband effectiveness, high detuning sensitivity and the dependence of its performance to the excitation frequency content should be resolved [9]. Therefore, in the past decade innovative modifications have been proposed to eliminate the aforementioned deficiencies [10-12]. Recently two innovative modifications of TMD have been introduced, the Tuned Mass Damper Inerter (TMDI) by Marian and Giaralis [13] and Tuned Tandem Mass Damper (TTMD) by Yang and Li [14] to improve the seismic performance of TMD. Additionally,
Cao and Li [15] mixed these two control devices and established Tuned Tandem Mass Damper-Inerter (TTMDI) to utilize both the tandem arrangement and the inerter device. Fig. 1 illustrates the classical TMD (Fig. 1(a)) and the recently proposed modifications (Figs. 1(b-d)). To fully exploit the control potential of the classical TMD, usually an optimization problem is defined with a set of three main dimensionless optimization variables i.e., mass, frequency and damping ratios [16]. Previous studies have ascertained that the monotonically increase of mass ratio improves the control performance of the TMD [17]; however, it is somewhat trivial that the mass ratio has a practical upper bound. The inerter (Fig. 1(e)) [18] is a two terminal device which provides an apparent mass without increasing the real mass of TMD. Although the inerter has the potential to pave the way for heavier TMDs to practically reach the higher mass ratio, the original ground-hooked version has practical limitations when applied in multi-story buildings as a roof-top TMDI. 


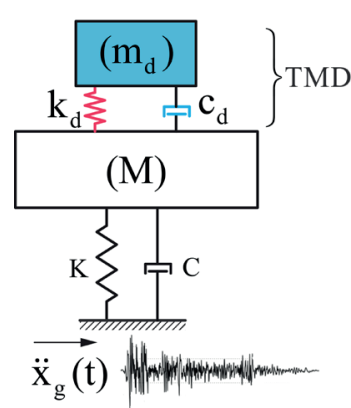

(a)

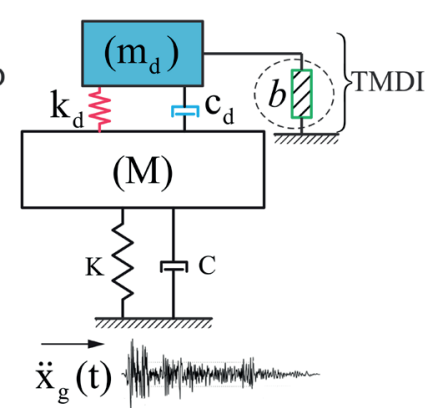

(b)

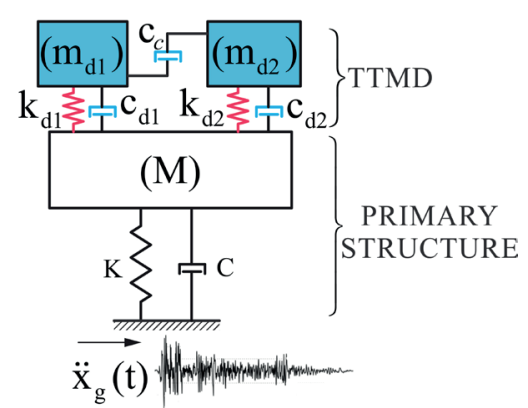

(c)

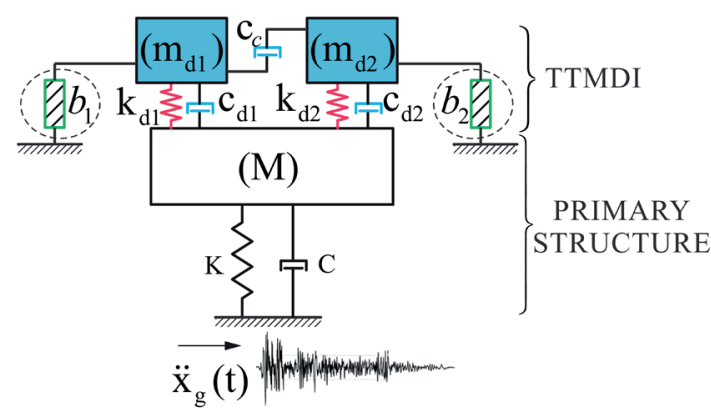

(d)
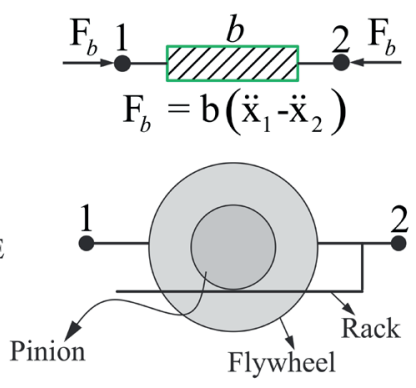

(e)

Fig. 1 Schematic presentation for: (a) TMD, (b) TMDI [13], (c) TTMD [14], (d) TTMDI [15], and

(e) ideal inerter and its rack and pinion realization

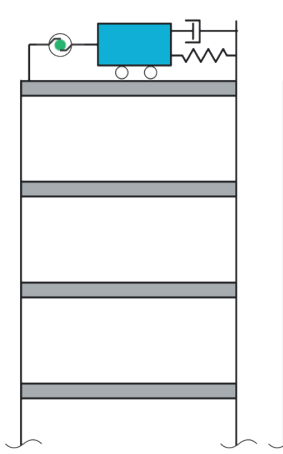

(a)

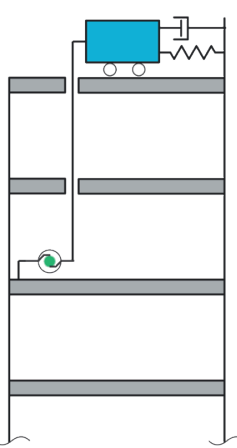

(b)

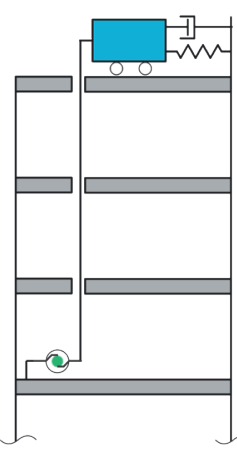

(c)

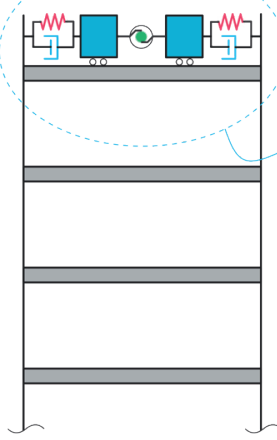

(d)

Fig. 2 Schematic illustration for a controlled N-story building with roof-top TMDI with the second terminal of inerter connected to: (a) roof, (b) two stories lower, and (c) three stories lower, and (d) proposed roof-top ICDTMD configuration

Kaveh et al. [9] showed that if the second terminal of the inerter is connected to the roof (Fig. 2(a)), the roof-top TMDI does not exhibit an efficient control performance. They further discussed that in order for the roof-top TMDI to be effective (and beat the performance of the classical TMD) in a multi-story building, the second terminal of the inerter should be connected to a different floor (Figs. 2(b) and 2(c)). Although, lowering the second terminal continuously improves the TMDI performance (i.e., it is well-recognized that the performance of Fig. 2(c) is better than Fig. 2(b)), the construction challenge increases rapidly as the second terminal is lowered to lower stories. Additionally, the inerter increases the mass at both ends, so in contrast to the ground-hooked version, connecting the second terminal of the inerter to floors [19] increase not only the mass of TMD, but also the mass of connected floor which can have undesirable effects on the seismic responses of the controlled building.

To address the above concerns, the Inerter-Connected Double Tuned Mass Damper (ICDTMD) is proposed as a new modification of the TMD that not only facilitates the implementation of TMDI from a construction perspective but also just amplifies the damper mass (Fig. 2(d)). Initially, the free vibration design parameters (as explained in Section 2) of the ICDTMD for passive control of a 10-story linear shear building is obtained using the particle swarm 
optimization algorithm (PSO) for different preselected values of mass and inertance ratios based on two separate objective functions, i.e., the $\mathrm{H}_{\infty}$ norm of roof displacement and story drift transfer functions. Furthermore, the performance of the optimized ICDTMD under 4 benchmark ground motions (i.e., two far- and two near-field records) is assessed through well-established performance criteria (story drift, story acceleration and story shear) and results are compared to those of the classical single TMD (STMD) and double TMD (DTMD). The roof-top DTMD is not well studied in the literature and this study also provides some insight about its performance.

\section{Models and methods}

To evaluate the performance of the introduced roof-top ICDTMD, three different roof-top configurations for TMD with the same total mass have been compared. In Fig. 3 these three configurations are presented as the classical STMD (Fig. 3(a)), DTMD (Fig. 3(b)) and the ICDTMD (Fig. 3(c)) where $m_{d 1}, c_{d 1}, k_{d 1}\left(m_{d 2}, c_{d 2}, k_{d 2}\right)$ denote the mass, the damping, and the stiffness of the first (second) TMD, respectively; and $b$ is the inertance ratio.

In Fig. 3(c), the viscous damper in the previously studied TMD [14] is substituted with an inerter as a linking element to increase the TMD mass only and not that of the floors. This proposed damper has seven design variables in comparison to three of the classical TMD, and therefore, its optimization process is much more sophisticated. The mass of the two TMDs and the inertance ratio (i.e., $m_{d 1}$, $m_{d 2}$ and $b$ in Fig. 3(c)) were preselected for practical purposes and the remaining four parameters, (i.e., $k_{d 1}, c_{d 1}, k_{d 2}$ and $c_{d 2}$ in Fig. 3(c)) were assumed as design variables for the optimization problem of the introduced damper.

The benefit of the proposed ICDTMD lies in the feature that the apparent mass of the inerter will only be added to the double masses of the TMDs and not to the floors. In addition, the inerter connection does not interfere with the building. The building used in this study is a benchmark 10-story linear shear building with $2 \%$ inherent damping [20, 21] well-recognized in the TMD community, with its dynamic properties presented in Table 1.

To obtain a comprehensive understanding of the control potential of STMD, DTMD, and ICDTMD, a set of dimensionless preselected variables, design variables and their studied ranges in Matlab vector notation are presented in Table 2.

$$
\begin{aligned}
& \boldsymbol{G}(s)_{\infty}=\max _{\omega} \sigma_{\max }(\boldsymbol{G}(i \omega)) \\
& |\boldsymbol{G}(s)|_{\infty}=\max _{\omega}(\boldsymbol{G}(i \omega))
\end{aligned}
$$

Table 1 Structural parameters of the 10-story benchmark building [20,21]

\begin{tabular}{lrrrrrrrrrr}
\hline Story & 1 & 2 & 3 & 4 & 5 & 6 & 7 & 8 & 9 & 10 \\
\hline $\begin{array}{l}\text { Mass } \\
\times\left(10^{3} \mathrm{~kg}\right)\end{array}$ & 179 & 170 & 161 & 152 & 143 & 134 & 125 & 116 & 107 & 98 \\
$\begin{array}{l}\text { Stiffness } \\
\times\left(10^{6} \mathrm{~N} / \mathrm{m}\right)\end{array}$ & 62.47 & 59.26 & 56.14 & 53.02 & 49.91 & 46.79 & 43.67 & 40.55 & 37.43 & 34.31 \\
\hline
\end{tabular}

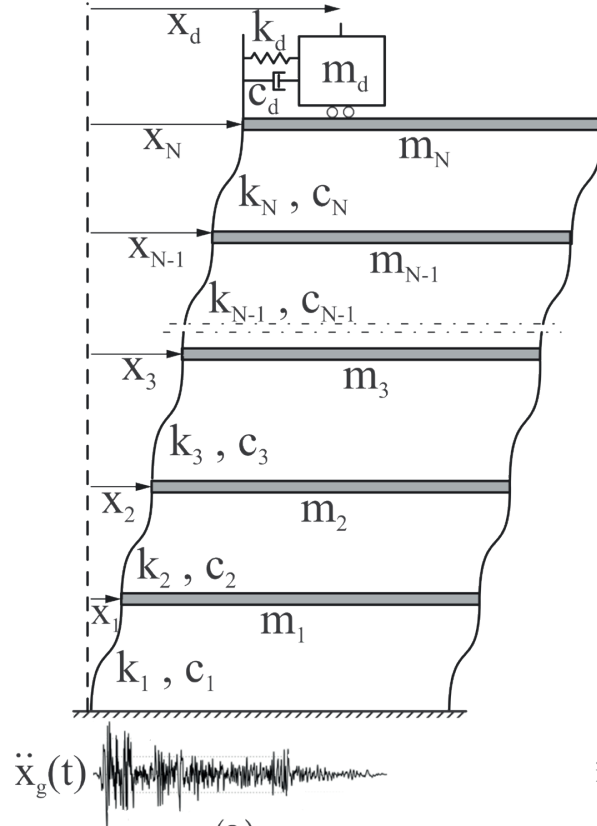

(a)

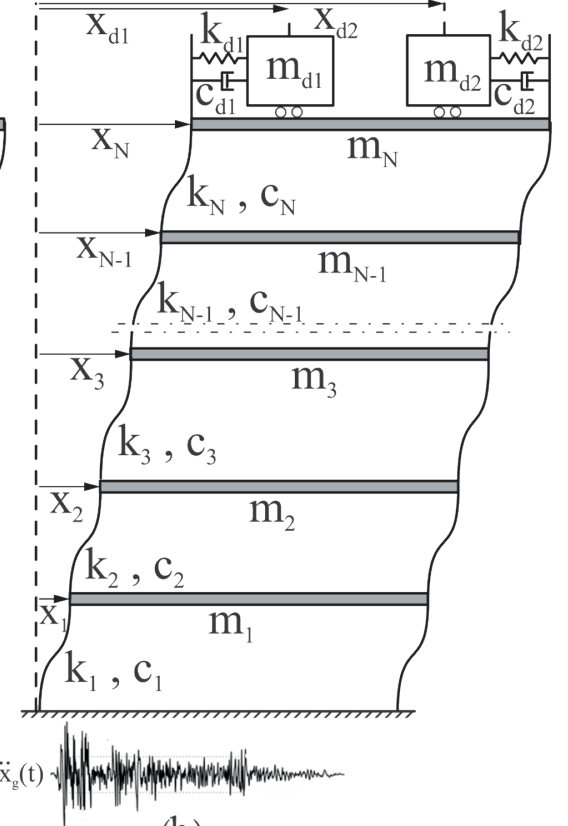

(b)

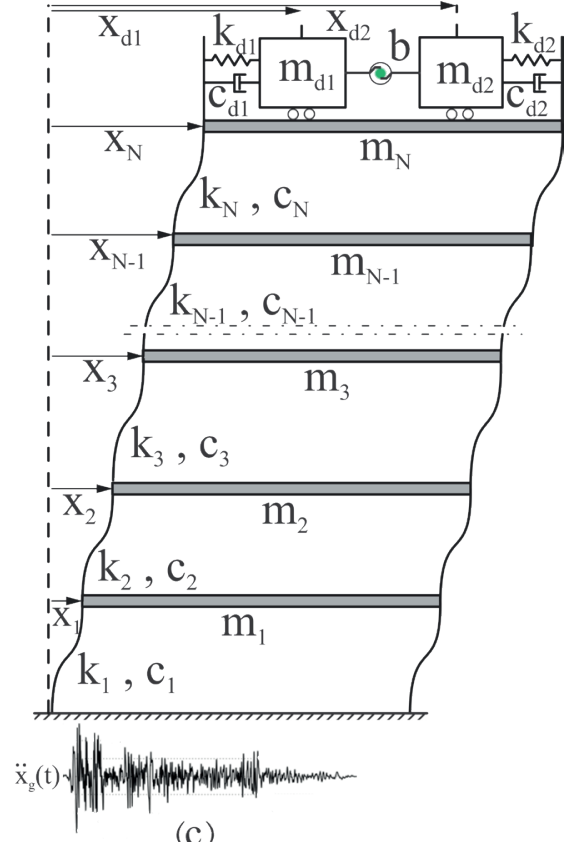

(c)

Fig. 3 Schematic illustration for the controlled N-story linear shear building with: (a) STMD, (b) DTMD, and (c) schematic diagram of ICDTMD 
Table 2 Optimization variable definitions and variable ranges

\begin{tabular}{|c|c|c|c|}
\hline \multicolumn{4}{|c|}{ Model Name } \\
\hline & STMD & DTMD & ICDTMD \\
\hline Preselected Variables & $\mu=\frac{m_{d}}{\mathrm{M}}$ & $\mu_{1}=\frac{m_{d 1}}{\mathrm{M}}$ & $\mu_{1}=\frac{m_{d 1}}{\mathrm{M}} \quad \mu_{2}=\frac{m_{d 2}}{\mathrm{M}}$ \\
\hline $\begin{array}{l}\text { Preselected Variable } \\
\text { Range }\end{array}$ & $\mu=[0.4,1,2,5,10,20]$ & $\begin{array}{c}\beta=[0] \\
\mu_{1}=\mu_{2}=[0.2,0.5,1,2.5,5,10]\end{array}$ & $\begin{array}{c}\beta=[0.05,0.1,0.2,0.25,0.3,0.5,1] \\
\mu_{1}=\mu_{2}=[0.2,0.5,1,2.5,5,10]\end{array}$ \\
\hline Design Variables & $f_{d}=\frac{\omega_{d}}{\omega_{1 s}}=\frac{\sqrt{\frac{k_{d}}{m_{d}}}}{\omega_{1 s}}$ & $f_{d 1}=\frac{\omega_{d 1}}{\omega_{1 s}}=\frac{\sqrt{\frac{k_{d 1}}{m_{d 1}+b}}}{\omega_{1 s}}$ & $f_{d 2}=\frac{\omega_{d 2}}{\omega_{1 s}}=\frac{\sqrt{\frac{k_{d 2}}{m_{d 2}+b}}}{\omega_{1 s}}$ \\
\hline & $\zeta_{d}=\frac{c_{d}}{2 m_{d} \omega_{d}}$ & $\zeta_{d 1}=\frac{c_{d 1}}{2\left(m_{d 1}+b\right) \omega_{d 1}}$ & $\zeta_{d 2}=\frac{c_{d 2}}{2\left(m_{d 1}+b\right) \omega_{d 2}}$ \\
\hline $\begin{array}{l}\text { Design Variable } \\
\text { Range }\end{array}$ & $\begin{array}{c}f_{d}=[0.0001: 0.0001: 2] \\
\zeta_{d}=[0: 0.0001: 2]\end{array}$ & $\begin{array}{r}f_{d 1}=f_{d 2} \\
\quad \zeta_{d 1}=\end{array}$ & $\begin{array}{l}1: 0.00001: 2] \\
00001: 2]\end{array}$ \\
\hline
\end{tabular}

In this study the preselected variables were the mass and inertance ratios for the STMD, DTMD and ICDTMD, respectively; while the design variable were the free vibration parameters (frequency and damping ratios) of the damper(s). The range of preselected variables includes practical limitations and even beyond to observe the variation of the optimum values of the design variables in comparison to the variation of the preselected variables. It should be noted that for simplicity the mass in the DTMD and ICDTMD cases is divided equally to produce the same overall mass ratio.

The selected objective functions for the optimization problem are minimizing the $\mathrm{H}_{\infty}$ norm of maximum interstory drift and maximum roof displacement as a measure for damage to structural elements and as an overall performance index of the control device, respectively. The former objective function (Eq. (1)) is $\infty$-norm of a multiple-input multiple-output (MIMO) transfer function $(G(i \omega))$, and the latter (Eq. (2)) is $\infty$-norm of a single-input single-output (SISO) transfer function of the combined host building and TMD-based control configuration, respectively.

\section{Optimum design of the control devices}

The optimum design of TMDs have been at the center of different researchers' interest since its introduction in the literature. Although many different analytical, quasi-analytical and even heuristic methods have been implemented for optimum design of a TMD, the metaheuristic algorithms are the only well-appreciated methods to find the optimum values of design parameters for a multi-degree-of-freedom (MDOF) building with inherent damping [22-25]. Nevertheless, for ICDTMD, the number of design variables (frequency and damping ratios for the two TMDs) is doubled, and an appropriate metaheuristic algorithm should be selected for the complex optimization problem. Particle swarm optimization (PSO) is a well-explored optimization algorithm in the optimum design of TMDs and its different forms $[14,26]$. Therefore, in this study PSO has been selected as the suitable algorithm for the optimization process. Further details on PSO algorithm framework can be found in the literature $[27,28]$.

It should be noted that the two main optimization approaches commonly adopted in the optimal design of the classical TMD or its modifications are: (i) the gradient based optimization method, such as Broyden-FletcherGoldfarb-Shanno (BFGS) quasi-Newton method; and (ii) the global optimization methods such as particle swarm optimization (PSO) algorithms [29].

The gradient-based optimization methods have been used by numerous researchers for optimal design of TMDs [30-33]. Yang et al. [29] reported that gradient-based optimization methods can accurately determine local optimum points, while to find global optimums researchers have used the global optimization methods, such as PSO [14], Charged System Search (CSS) [1, 24], Colliding Bodies Optimization (CBO) [16, 25], Genetic Algorithm (GA) [34], Simulated Annealing (SA) [35], among others. However, the focus of this paper is on the performance evaluation of a newly proposed tandem based TMDI. The comparison between different optimization methods is out of the scope of the current study and can be performed in future studies.

For the purposes of this study the optimal free vibration parameters for different combination of mass ratio $(\mu)$ and inertance ratio $(\beta)$ are calculated for the STMD, DTMD and ICDTMD considering an inherent damping of $2 \%$. The results for STMD and DTMD at the roof are also included for comparison. Table 3 shows the optimal 
Table 3 Optimal parameters for different control devices based on minimizing the $\mathrm{H} \infty$ norm of roof displacements

\begin{tabular}{|c|c|c|c|c|c|c|c|c|c|c|c|c|c|c|c|c|c|}
\hline & \multicolumn{3}{|c|}{$\begin{array}{l}\text { Preselected } \\
\text { Parameters }\end{array}$} & \multicolumn{4}{|c|}{ Optimum Parameters } & \multirow{2}{*}{$\begin{array}{l}\text { Max } \\
\text { Disp. } \\
\text { ratio }\end{array}$} & & \multicolumn{3}{|c|}{$\begin{array}{l}\text { Preselected } \\
\text { Parameters }\end{array}$} & \multicolumn{4}{|c|}{ Optimum Parameters } & \multirow{2}{*}{$\begin{array}{l}\text { Max } \\
\text { Disp } \\
\text { ratio }\end{array}$} \\
\hline & $\beta$ & $\mu_{1}$ & $\mu_{2}$ & $f d_{1}$ & $\zeta_{d 1}$ & $f d_{2}$ & $\zeta_{d 1}$ & & & $\beta$ & $\mu_{1}$ & $\mu_{2}$ & $f d_{1}$ & $\zeta_{d 1}$ & $f d_{2}$ & $\zeta_{d 1}$ & \\
\hline \multirow{7}{*}{ STMD } & \multirow[t]{7}{*}{-} & 0.4 & 0 & 0.988 & 0.059 & 0 & 0 & 0.416 & & \multirow[t]{7}{*}{-} & 0.2 & 0.2 & 1.021 & 0.031 & 0.965 & 0.036 & 0.376 \\
\hline & & 1 & 0 & 0.974 & 0.088 & 0 & 0 & 0.308 & & & 0.5 & 0.5 & 1.03 & 0.054 & 0.943 & 0.051 & 0.277 \\
\hline & & 2 & 0 & 0.952 & 0.123 & 0 & 0 & 0.241 & & & 1 & 1 & 0.917 & 0.081 & 1.032 & 0.079 & 0.213 \\
\hline & & 5 & 0 & 0.891 & 0.193 & 0 & 0 & 0.174 & \multirow[t]{4}{*}{ DTMD } & & 2.5 & 2.5 & 0.857 & 0.12 & 1.03 & 0.132 & 0.147 \\
\hline & & 10 & 0 & 0.8 & 0.271 & 0 & 0 & 0.138 & & & 5 & 5 & 0.788 & 0.186 & 0.994 & 0.228 & 0.112 \\
\hline & & 15 & 0 & 0.719 & 0.331 & 0 & 0 & 0.123 & & & 7.5 & 7.5 & 0.728 & 0.226 & 0.956 & 0.285 & 0.094 \\
\hline & & 20 & 0 & 0.648 & 0.382 & 0 & 0 & 0.115 & & & 10 & 10 & 0.675 & 0.241 & 0.925 & 0.316 & 0.083 \\
\hline \multirow{7}{*}{ ICDTMD } & \multirow[t]{7}{*}{0.05} & 0.2 & 0.2 & 0.261 & 0 & 0.08 & 0.056 & 0.413 & & \multirow[t]{7}{*}{0.1} & 0.2 & 0.2 & 0 & 1.222 & 0.195 & 0.011 & 0.413 \\
\hline & & 0.5 & 0.5 & 0.057 & 0.265 & 0.406 & 0 & 0.309 & & & 0.5 & 0.5 & 0.3 & 0.023 & 0 & 1.03 & 0.307 \\
\hline & & 1 & 1 & 0.534 & 0 & 0.066 & 0.726 & 0.241 & & & 1 & 1 & 0.021 & 1.097 & 0.404 & 0 & 0.238 \\
\hline & & 2.5 & 2.5 & 0.622 & 0.043 & 0.413 & 0.268 & 0.166 & \multirow[t]{4}{*}{ ICDTMD } & & 2.5 & 2.5 & 0.553 & 0 & 0.125 & 0.725 & 0.168 \\
\hline & & 5 & 5 & 0.64 & 0 & 0.667 & 0.349 & 0.117 & & & 5 & 5 & 0.544 & 0 & 0.482 & 0.33 & 0.12 \\
\hline & & 7.5 & 7.5 & 0.65 & 0 & 0.758 & 0.356 & 0.094 & & & 7.5 & 7.5 & 0.565 & 0 & 0.569 & 0.399 & 0.099 \\
\hline & & 10 & 10 & 0.756 & 0.383 & 0.624 & 0.064 & 0.083 & & & 10 & 10 & 0.596 & 0 & 0.625 & 0.477 & 0.085 \\
\hline \multirow{7}{*}{ ICDTMD } & \multirow[t]{7}{*}{0.2} & 0.2 & 0.2 & 0.139 & 0.007 & 0 & 0.867 & 0.412 & & \multirow[t]{7}{*}{0.3} & 0.2 & 0.2 & 0 & 0.317 & 0.114 & 0.006 & 0.412 \\
\hline & & 0.5 & 0.5 & 0.057 & 0.017 & 0.209 & 0.013 & 0.305 & & & 0.5 & 0.5 & 0.177 & 0 & 0.002 & 1.586 & 0.305 \\
\hline & & 1 & 1 & 0.296 & 0 & 0.012 & 0.936 & 0.237 & & & 1 & 1 & 0.244 & 0.028 & 0 & 1.225 & 0.236 \\
\hline & & 2.5 & 2.5 & 0.424 & 0.026 & 0.034 & 0.871 & 0.166 & \multirow[t]{4}{*}{ ICDTMD } & & 2.5 & 2.5 & 0.008 & 0.744 & 0.357 & 0.055 & 0.165 \\
\hline & & 5 & 5 & 0.382 & 0.242 & 0.402 & 0 & 0.121 & & & 5 & 5 & 0.254 & 0.26 & 0.387 & 0.006 & 0.122 \\
\hline & & 7.5 & 7.5 & 0.444 & 0 & 0.426 & 0.331 & 0.101 & & & 7.5 & 7.5 & 0.07 & 1.286 & 0.482 & 0.058 & 0.105 \\
\hline & & 10 & 10 & 0.476 & 0 & 0.449 & 0.43 & 0.089 & & & 10 & 10 & 0.44 & 0.002 & 0.334 & 0.454 & 0.089 \\
\hline \multirow{7}{*}{ ICDTMD } & \multirow[t]{7}{*}{0.5} & 0.2 & 0.2 & 0 & 1.185 & 0.088 & 0.004 & 0.412 & & \multirow[t]{7}{*}{1} & 0.2 & 0.2 & 0 & 1.377 & 0.063 & 0.001 & 0.412 \\
\hline & & 0.5 & 0.5 & 0 & 0.482 & 0.138 & 0.011 & 0.305 & & & 0.5 & 0.5 & 0.098 & 0.007 & 0 & 0.679 & 0.304 \\
\hline & & 1 & 1 & 0 & 0.136 & 0.191 & 0.023 & 0.236 & & & 1 & 1 & 0 & 0.851 & 0.136 & 0.016 & 0.235 \\
\hline & & 2.5 & 2.5 & 0.005 & 0.455 & 0.283 & 0.049 & 0.164 & ICDTMD & & 2.5 & 2.5 & 0.202 & 0.006 & 0.022 & 0.332 & 0.163 \\
\hline & & 5 & 5 & 0.005 & 0.905 & 0.361 & 0.096 & 0.123 & & & 5 & 5 & 0.264 & 0.078 & 0.002 & 0.343 & 0.122 \\
\hline & & 7.5 & 7.5 & 0.381 & 0 & 0.15 & 0.505 & 0.103 & & & 7.5 & 7.5 & 0.295 & 0 & 0.037 & 1.039 & 0.102 \\
\hline & & 10 & 10 & 0.412 & 0 & 0.136 & 0.77 & 0.091 & & & 10 & 10 & 0.06 & 0.603 & 0.309 & 0.051 & 0.091 \\
\hline
\end{tabular}

free parameters for different preselected values of mass and inertance ratios based on minimizing the $\mathrm{H}_{\infty}$ norm of roof displacement using PSO algorithm.

The normalized maximum frequency response function (FRF) of roof displacement, defined as the ratio of the maximum roof displacement in the controlled to the uncontrolled state in the frequency domain, is also reported for comparison purposes. Different mass ratios ranging from $0.4 \%$ to $20 \%$ are preselected, while for the inertance pre-selected values are as small as $5 \%$ up to as high as $100 \%$. As mentioned earlier, equal masses are assumed for the DTMD to make up a similar value as the STMD. Comparing the normalized FRF of roof displacement (second objective function) for the STMD and DTMD configuration, it can be concluded that the DTMD performs slightly better (about an average of $8.5 \%$ ); while the performance of the ICDTMD with small inertance of 0.05 is similar to a STMD for values of mass ratio, $\mu$, smaller than 0.15 and similar to DTMD for higher mass ratios. The performance of the ICDTMD for the remaining inertances is similar to the STMD case. It is interesting to note that while the normalized displacement does not seem to show a significant improvement with the introduction of inertance, the optimal frequency ratios exhibit a significant reduction, especially for smaller mass and inertance ratios. A similar trend is observed for the FRF of story drifts (first objective function), which is omitted herein for the sake of brevity.

Fig. 4 shows the frequency response of story drift ratio (singular value) for the structure with optimal STMD, DTMD and ICDTMD (for two inertance ratios of 0.05 and 1 as 
lower and upper limits for inertance, respectively) and for two preselected mass ratios of $0.4 \%$ and $20 \%$. The results for the uncontrolled structure are also presented for comparison purposes. Fig. 5 shows the same diagrams for the second objective function, i.e., FR of roof displacement.

Both Figs. 4 and 5 indicate that for a mass ratio of $0.4 \%$, the STMD and ICDTMD provide the same level of response mitigation with respect to the uncontrolled structure for the first mode, while the DTMD has outperformed the alternative control devices. In addition, for a mass ratio of $0.4 \%$, the reduction in structural response for the second mode is almost of the same order for all control devices. However, it should be noted that according to Table 3, the ICDTMD requires smaller spring stiffness for this level of response reduction. For a mass ratio of $20 \%$, a larger reduction in structural response is observed for all cases and the effect of inertance becomes slightly more profound for the first mode. Unlike the smaller mass ratio of $0.4 \%$, the DTMD provides a similar response reduction as the other control devices for the first mode, while in the second mode a similar behavior as for the smaller mass ratio of $0.4 \%$ is observed. In addition, for all cases the response has been reduced with respect to the uncontrolled state.
For better understanding from a practical point of view, the stiffness of the spring and normalized frequency responses of the ICDTMD with different values of inertance and mass ratios for the second objective function (minimization of $\mathrm{H} \infty$ norm of roof displacement) have been compared to the corresponding values for STMD and DTMD in the frequency domain. Fig. 6 shows the reduction in spring stiffness (Fig. 6(a) and 6(b)) and normalized FRF with respect to the corresponding (6(c) and 6(d)) STMD and DTMD values for different values of inertance and mass ratios. Fig. 6 a shows that except for some limited cases ( $\mu=5 \%$ and $\beta=10 \% ; \mu=10 \%$ and $\beta=30 \%$ ) the stiffness of the ICDTMD spring is slightly higher than that of the STMD, while in the case of the DTMD (Fig. 6(b)) the opposite is observed, i.e., the ICDTMD spring stiffness is significantly lower (up to $80 \%$ less) than that of the DTMD. Fig. 6(a) and 6(b) also indicate that, except for some limited cases, despite obtaining different frequency ratios, the overall variation in stiffness reduction for different inertance ratios is less than $10 \%$. Fig. 6(c) and 6(d) compare the percentage reduction in roof displacement for the ICDTMD-controlled building with respect to the STMD and DTMD-controlled building, respectively.

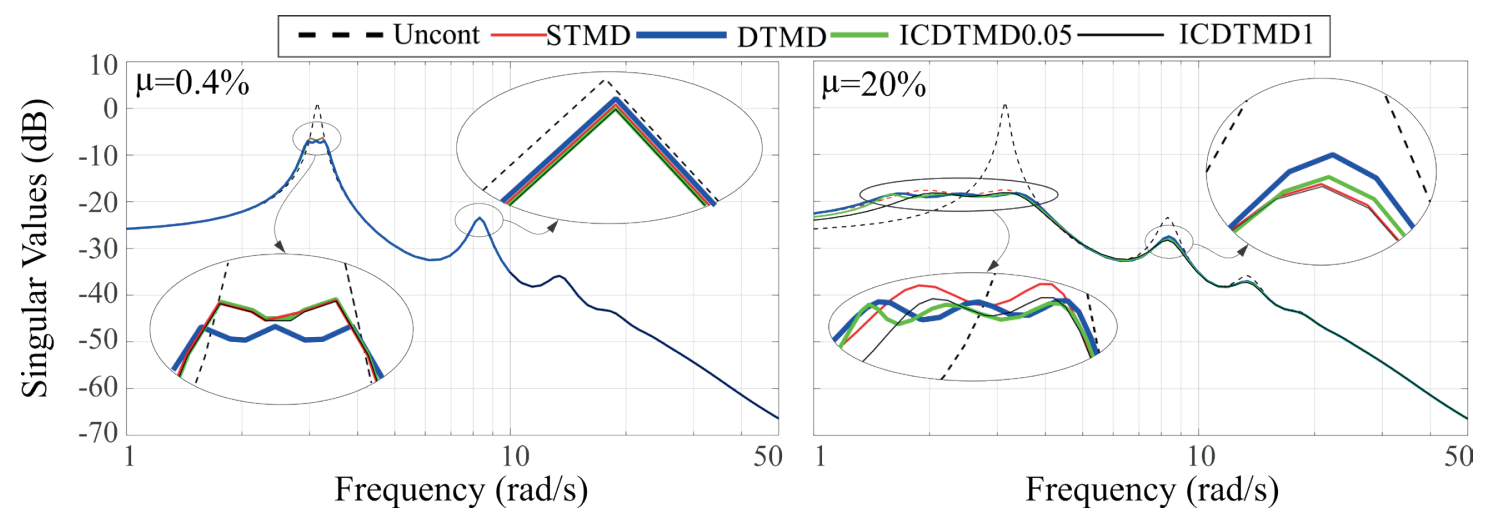

Fig. 4 Frequency response of story drift for different cases for (a) $\mu=0.4 \%$ and (b) $\mu=20 \%$

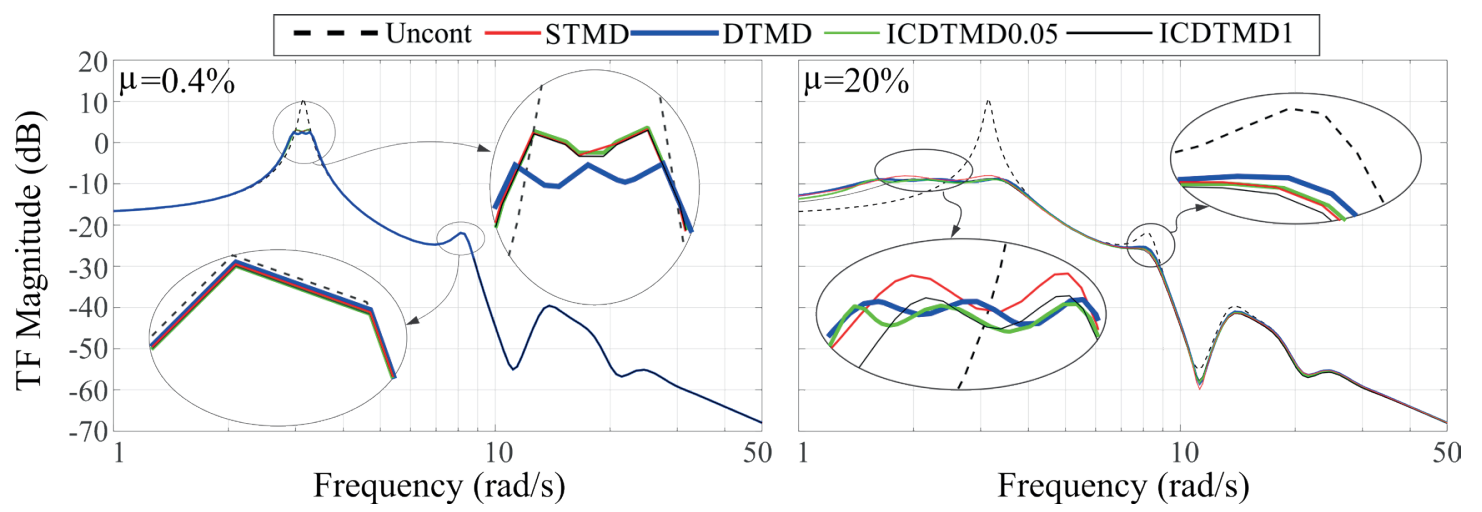

Fig. 5 Frequency response of roof displacement for different cases for (a) $\mu=0.4 \%$ and (b) $\mu=20 \%$ 
Fig. 6(c) indicates that except for some limited cases (with an increase of about 1\%) the FRF of roof displacement has been slightly reduced up to $10 \%$ with respect to the STMD-equipped building, while Fig. 6(d) shows that the response has increased up to $10 \%$ with respect to the DTMD-equipped building. However, comparing Fig. 6(b) and Fig. 6(d) shows that despite the significant reduction in spring stiffness with respect to the DTMD, the response has only increased by $10 \%$. Therefore, with introduction of inertance and using the ICDTMD, the same level of responses with a smaller spring stiffness can be obtained, which is a great benefit of the proposed method from a practical point of view. Fig. 6 also allows for a better decision making from a designer's perspective: The ICDTMD generally provides smaller responses, while the stiffness has increased with respect to the STMD case. However, the redundancy of the ICDTMD with two masses, will result in a more "reliable" performance.

\section{Seismic performance evaluation of optimum designed ICDTMD}

Next, the performance of the controlled structure with different control devices, i.e., STMD, DTMD and ICDTMD, is evaluated in the time domain. To this end three perfor-
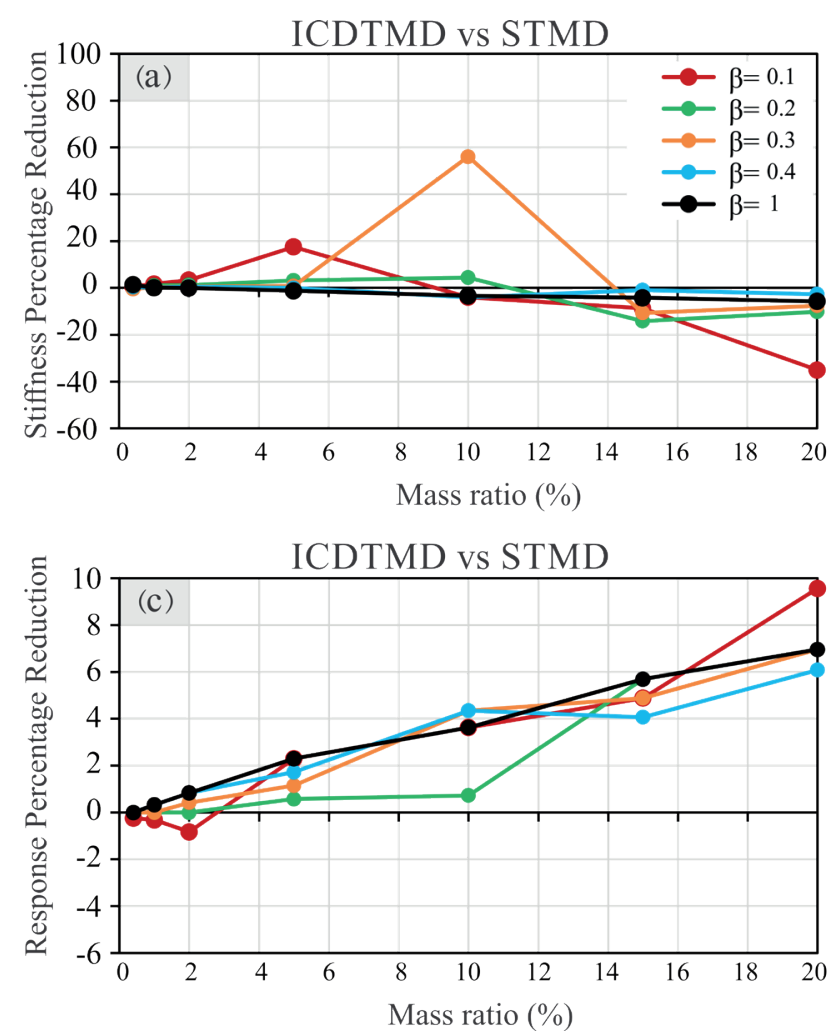

mance indices are evaluated under 4 benchmark records [36] commonly used for control problems, i.e., El-Centro and Hachinohe (as far-field records), and Kobe and Northridge (as near-field records) shown in Table 4 and Fig. 7. The selected performance indices are the normalizedmaximum story drift, story acceleration and story shear.

Fig. 8 shows the maximum normalized story drifts for the uncontrolled and controlled 10-story building under the aforementioned far field (El-Centro and Hachinohe) and near field (Kobe and Northridge) records. Results in Fig. 8 are presented for the control devices (STMD, DTMD, and ICDTMD) tuned to minimize the second objective function, i.e., minimizing the $\mathrm{H}_{\infty}$ of roof displacement when the mass ratio is selected as $20 \%$. Results show that overall, all tuned control devices have successfully reduced the story drifts with respect to the uncontrolled state under both far and near field records, with the highest and lowest

\begin{tabular}{lccc}
\multicolumn{4}{c}{ Table 4 seismic record information in this study [36] } \\
\hline Name & Earthquake/Station & Year & Component \\
\hline El-Centro & Imperial Valley/El Centro Station & 1940 & N-S \\
Hachinohe & Tokachi-Oki/Hachinohe & 1968 & N-S \\
Kobe & Hyogo-ken/KJMA & 1995 & N-S \\
Northridge & Northridge/SCH & 1994 & N-S \\
\hline
\end{tabular}
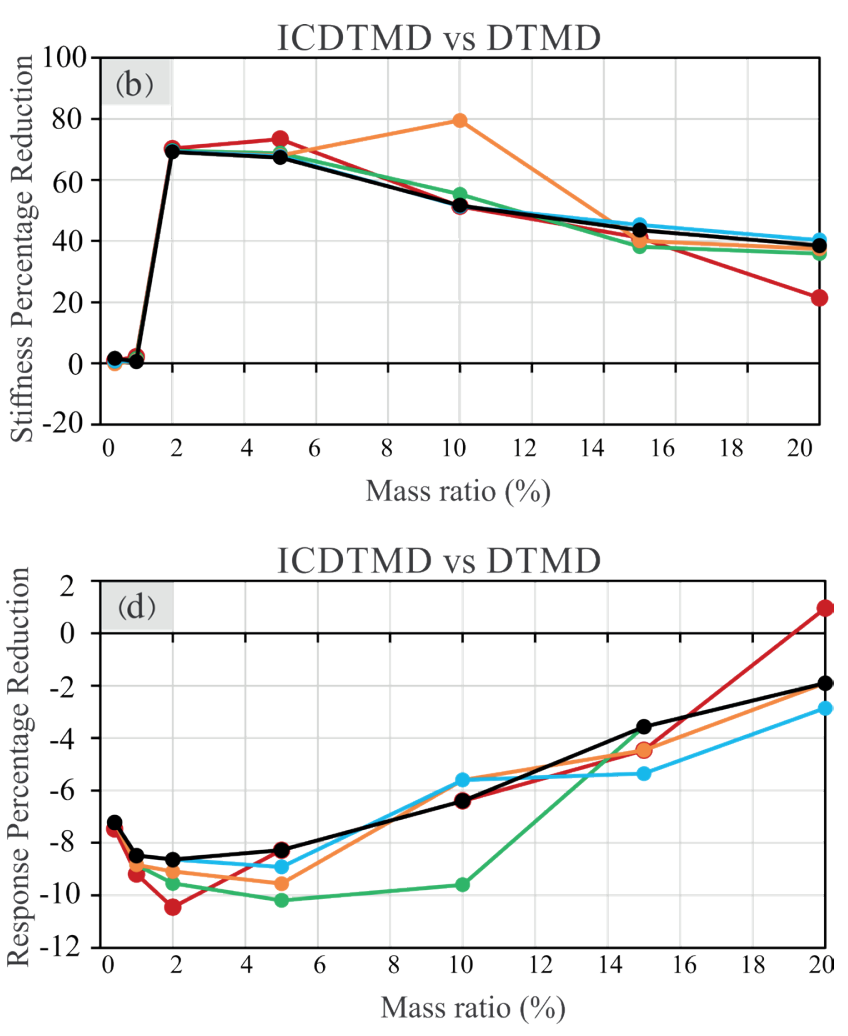

Fig. 6 Reduction in spring stiffness of the ICDTMD with respect to (a) STMD, (b) DTMD; roof displacement FRF reduction with respect to (c) STMD and (d) DTMD 


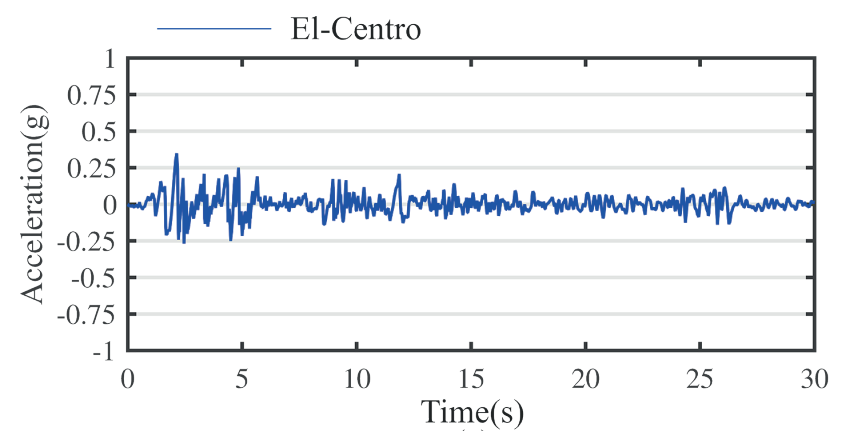

(a)

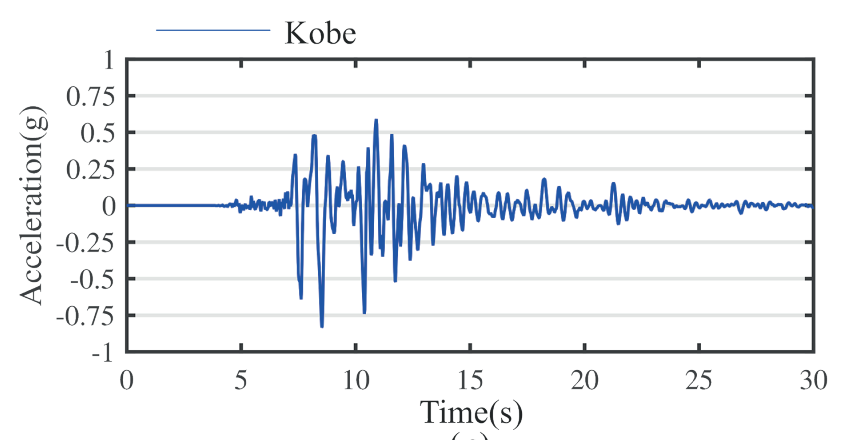

(c)

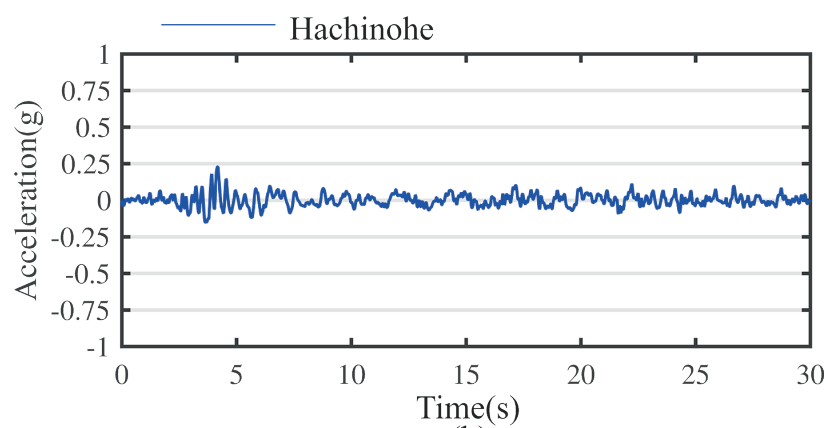

(b)

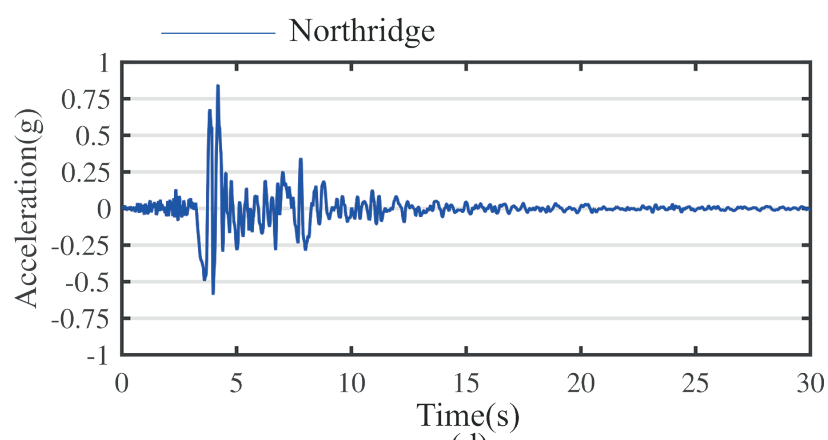

(d)

Fig. 7 Time histories of the benchmark records: (a) El-Centro, (b) Hachinohe, (c) Kobe, (d) Northridge
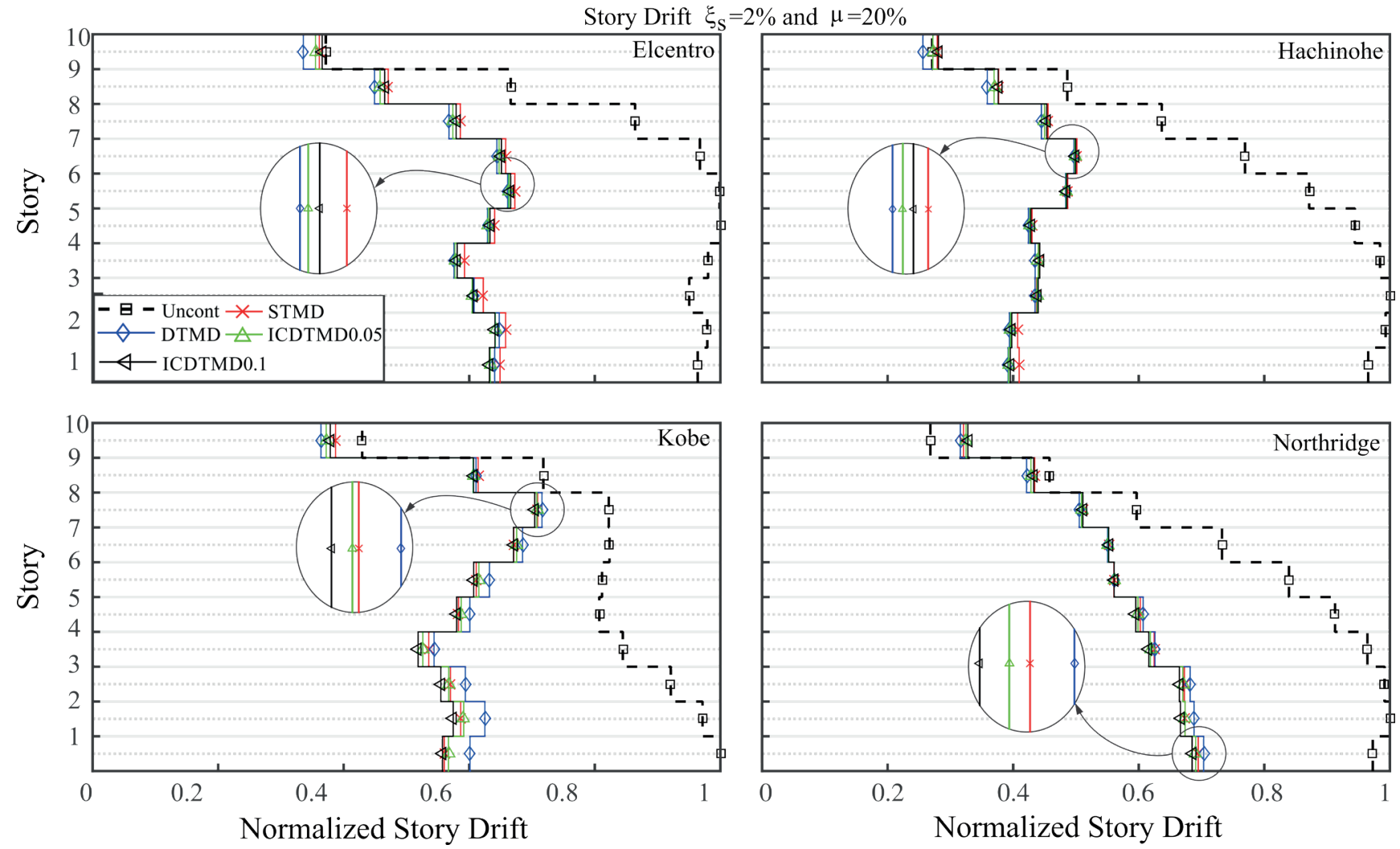

Fig. 8 Maximum normalized story drift for different control devices and different records 
reductions observed for the first and 10th story, respectively. The only exception is the 10th story drift under the Northridge record, where the control devices have amplified the story drifts that is probably caused by the pulse nature of the record. In addition, the proposed control methods have been more efficient to reduce the story drifts in the lower stories. Comparing the control device performance, it can be noted that a small addition of inertance (ICDTMD0.05 and ICDTMD0.1 with 5\% and 10\% inertance ratios, respectively), has resulted in a generally similar (slightly better) response with respect to the STMD. It is interesting to note that the DTMD has outperformed the other control devices under far field records, while the opposite is observed for near field records.

Similar to Fig. 8, Fig. 9 illustrates the maximum normalized story acceleration for the uncontrolled and controlled 10-story building. Results show that unlike for story drifts, the control devices are more efficient in reducing the story accelerations in the upper stories.

The average maximum reduction in the story acceleration for the far field records is about $40 \%$, while for the near field records this number is about $20 \%$. Therefore, the control devices have performed more efficiently under the far field records. Nevertheless, for all records the maximum story acceleration in the controlled state is always lesser or equal to that in the uncontrolled state, providing a robust control method. Comparing the control device performance, it can be noted that the ICDTMD with small inertances of $5 \%$ and $10 \%$ have resulted in a generally slightly better or similar response with respect to the STMD and DTMD. Furthermore, the ICDTMD shows a better and more robust performance compared to a conventional rooftop TMDI [9, 37].

Finally, Fig. 10 shows the maximum normalized story shears for the uncontrolled and controlled structure. Similar to story drifts, all control devices have successfully reduced the story and base shears, except for the 10th story shear under the Northridge earthquake. The average maximum base shear reduction for all controlled states under far field records is approximately $46 \%$ with respect to the uncontrolled state, while for the near filed records an average maximum reduction of $36 \%$ is observed. Therefore, the control strategy has been successful in reducing the base and story shear. The maximum $60 \%$ in base shear reduction is observed under the Hachinohe earthquake. Comparing the control device performances, it can be noted that the ICDTMD with small inertances of $5 \%$ and $10 \%$ have resulted in a generally slightly better or
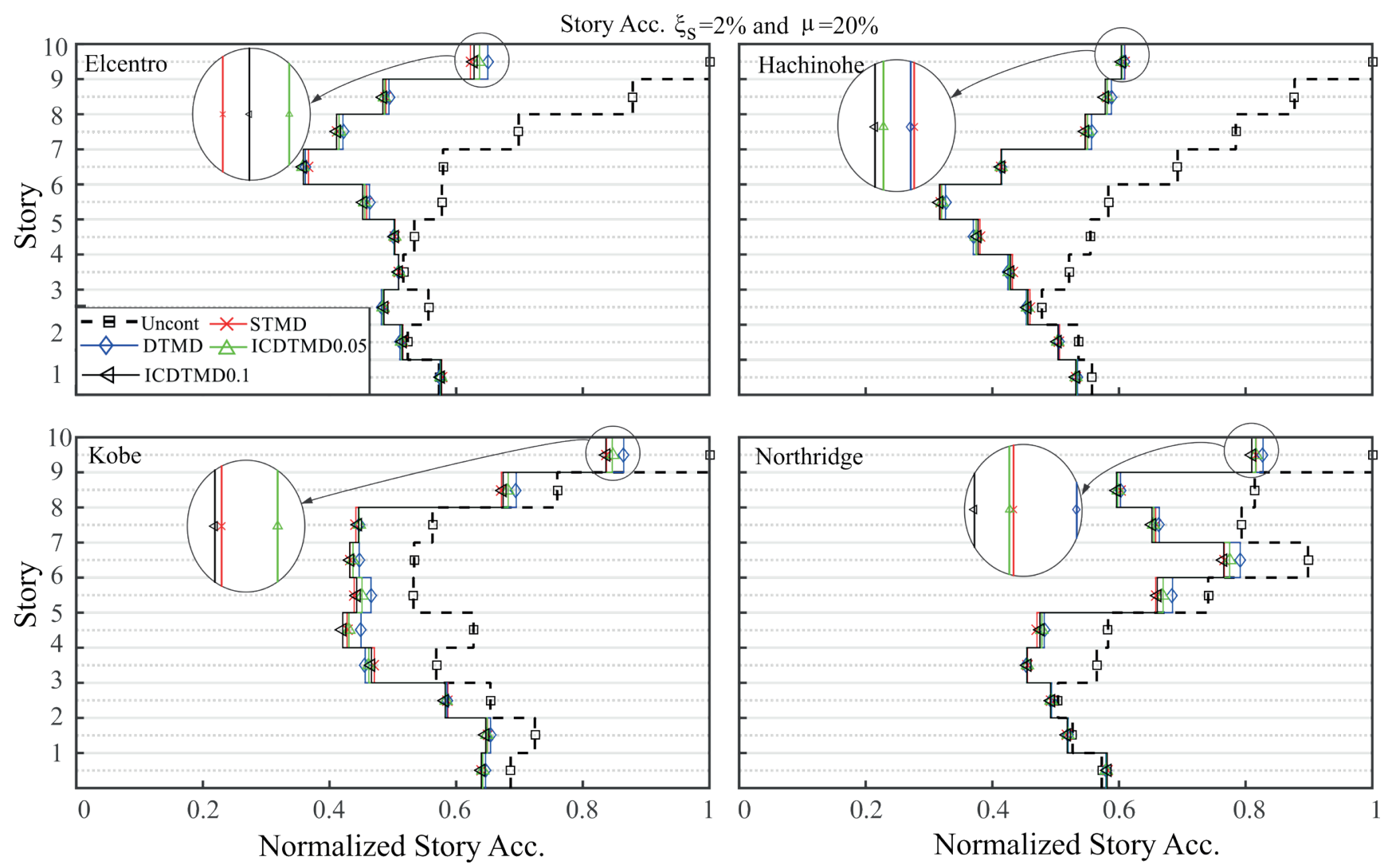

Fig. 9 Maximum normalized story acceleration for different control devices and different records 

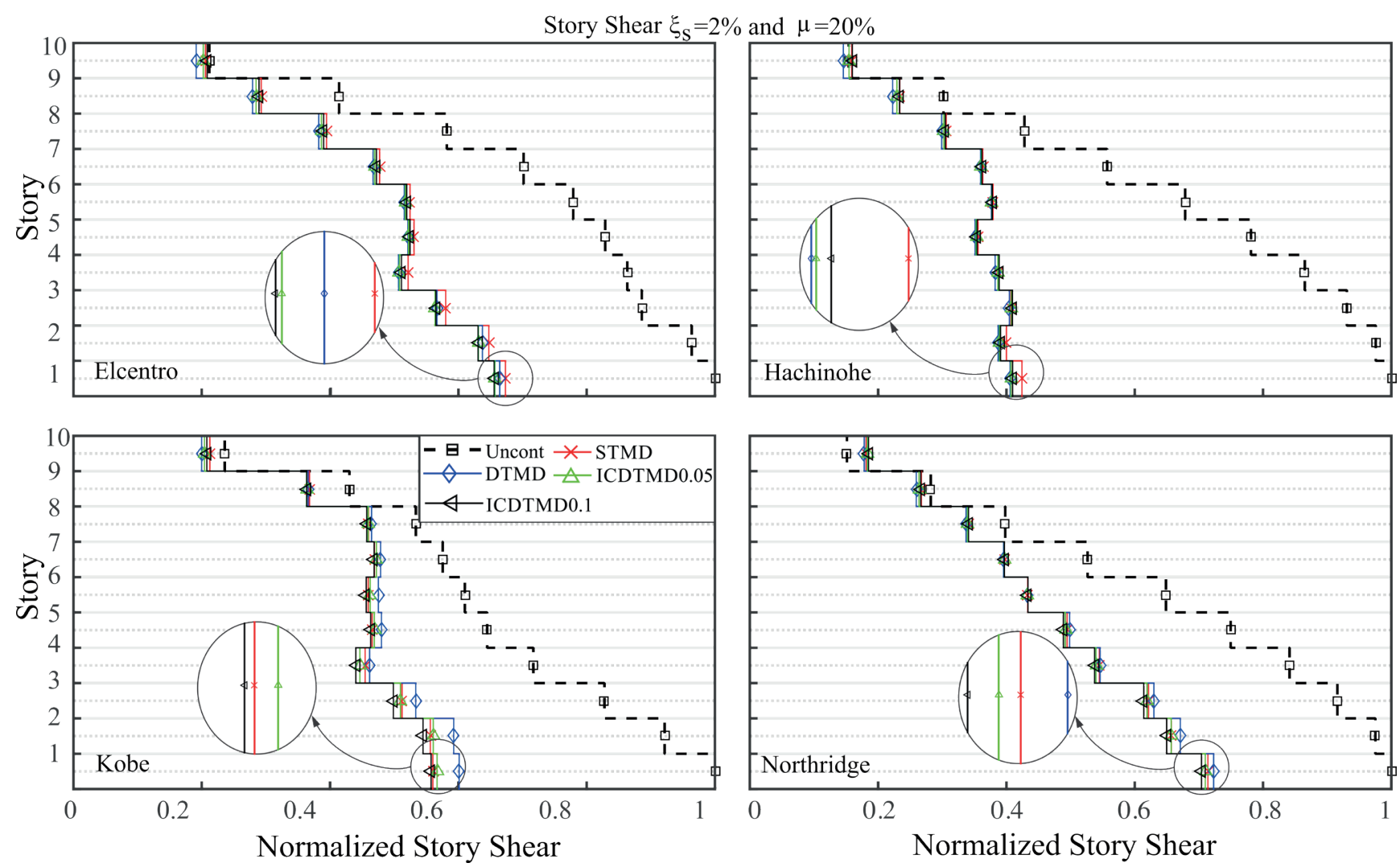

Fig. 10 Maximum normalized story shears for different control devices and different records

similar response with respect to the STMD and DTMD. It should be noted that very similar performances are observed when the control devices are optimized to minimize the $\mathrm{H} \infty$ of story drifts. However, for the sake of brevity only results for the second objective function was presented herein. All performance indices indicate a similar or better response to the STMD and DTMD when the ICDTMD is installed on rooftop. Previous studies [9, 37] have shown that inerters are efficient when the second terminal is connected to the lower stories, while the current study has provided a new approach for the inerter to be effective while being installed at rooftop.

\section{Summary and conclusions}

In current work the Inerter-Connected Double Tuned Mass Damper (ICDTMD) is introduced for the structural control of a well-recognized benchmark 10 -story linear shear building. The ICDTMD aims at overcoming the practical limitations of the roof-top tuned mass damper inerter (TMDI), in which the second terminal of the inerter is connected to lower stories to be comparable with the conventional single TMD (STMD) and double TMD (DTMD) installed at the rooftop. Particle swarm optimization (PSO) algorithm is employed to obtain the free parameters of the control devices (STMD, DTMD and ICDTMD) for different preselected values of mass and inertance ratios using two different single objective functions, i.e., the $\mathrm{H}_{\infty}$ norms of story drifts and roof displacement were minimized for robust tuning. To evaluate the performance of the proposed device, results are compared to that of a STMD and DTMD in both the frequency and time domains. Results of the frequency domain analysis show that in general for both objective functions the DTMD performs better than the STMD, while with the introduction of inertance (ICDTMD), responses are within 10\% of the STMD case. In addition, the ICDTMD has the benefit of providing more redundancy compared to a STMD and is therefore, more reliable. Furthermore, the optimized spring stiffness of the ICDTMD was significantly smaller than that of the DTMD, while the response was only amplified by $10 \%$. However, the opposite was observed when results were compared to the STMD-controlled structure, i.e., the optimized spring stiffness for the ICDTMD was slightly higher, while the response was reduced by a maximum of $10 \%$. It should be noted that in all cases, the response of the controlled structure was less than that of the uncontrolled structure, which emphasizes the robustness of the proposed method. Finally, the performance of the controlled structure equipped with 
STMD, DTMD and ICDTMD is evaluated under four benchmark records (El-Centro and Hachinohe as far-field records, and Kobe and Northridge as near-field records) in terms of normalized maximum story drift, story acceleration and story shears. Results of the time domain analysis for both objective functions illustrate that the proposed control methods have been more efficient to reduce the story drifts for the lower stories, while the control devices

\section{References}

[1] Kaveh, A., Pirgholizadeh, S., Khadem Hosseini, O. "Semi-active tuned mass damper performance with optimized fuzzy controller using CSS algorithm", Asian Journal of Civil Engineering, 16(5), pp. 587-606, 2015. [online] Available at: https://www.sid.ir/en/ Journal/ViewPaper.aspx?ID $=525630$

[2] Dai, J., Xu, Z.-D., Gai, P.-P. "Parameter determination of the tuned mass damper mitigating the vortex-induced vibration in bridges", Engineering Structures, 221, Article number: 111084, 2020. https://doi.org/10.1016/j.engstruct.2020.111084

[3] Zhang, Y., Zhao, X., Wei, X. "Robust structural control of an underactuated floating wind turbine", Wind Energy, 23(12), pp. 2166$2185,2020$.

https://doi.org/10.1002/we.2550

[4] Fahimi Farzam, M., Alinejad, B., Bekdaş, G., Gavgani, S. A. M. "Control of a Jacket Platform Under Wave Load Using ATMD and Optimization by HSA", In: 6th International Conference on Harmony Search, Soft Computing and Applications, Istanbul, Turkey, 2020, pp. 45-51.

https://doi.org/10.1007/978-981-15-8603-3_5

[5] Elias, S., Matsagar, V., Datta, T. K. "Along-wind response control of chimneys with distributed multiple tuned mass dampers", Structural Control and Health Monitoring, 26(1), Article ID e2275, 2019. https://doi.org/10.1002/stc.2275

[6] Tian, L., Zhou, M., Qiu, C., Pan, H., Rong, K. "Seismic response control of transmission tower-line system using SMA-based TMD", Structural Engineering and Mechanics, 74(1), pp. 129-143, 2020. https://doi.org/10.12989/sem.2020.74.1.129

[7] Elias, S., Matsagar, V. "Research developments in vibration control of structures using passive tuned mass dampers", Annual Reviews in Control, 44, pp. 129-156, 2017. https://doi.org/10.1016/j.arcontrol.2017.09.015

[8] Gutierrez Soto, M., Adeli, H. "Tuned Mass Dampers", Archives of Computational Methods in Engineering, 20(4), pp. 419-431, 2013. https://doi.org/10.1007/s11831-013-9091-7

[9] Kaveh, A., Fahimi Farzam, M., Hojat Jalali, H. "Statistical seismic performance assessment of tuned mass damper inerter", Structural Control and Health Monitoring, 27(10), Article ID e2602, 2020. https://doi.org/10.1002/stc.2602

[10] Mirza Hessabi, R., Mercan, O. "Investigations of the application of gyro-mass dampers with various types of supplemental dampers for vibration control of building structures", Engineering Structures, 126, pp. 174-186, 2016. https://doi.org/10.1016/j.engstruct.2016.07.045 are more efficient in reducing the story accelerations in the upper stories. All performance indices indicate a similar or better response to the STMD and DTMD when the ICDTMD is installed on rooftop. Previous studies have shown that inerters are efficient when the second terminal is connected to the lower stories, while the current study has provided a new approach for the inerter to be effective while being installed at rooftop.

[11] Salvi, J., Rizzi, E., Rustighi, E., Ferguson, N. S. "On the optimization of a hybrid tuned mass damper for impulse loading", Smart Materials and Structures, 24(8), Article number: 085010, 2015. https://doi.org/10.1088/0964-1726/24/8/085010

[12] Fahimi Farzam, M., Jalali, H. H., Gavgani, S. A. M., Kayabekir, A. E., Bekdaş, G. "Current Trends in the Optimization Approaches for Optimal Structural Control", In: Advances in Structural Engineering - Optimization, Springer, Cham, Switzerland, 2021, pp. 133-179. https://doi.org/10.1007/978-3-030-61848-3_5

[13] Marian, L., Giaralis, A. "Optimal design of inerter devices combined with TMDs for vibration control of buildings exposed to stochastic seismic excitations", In: 11th International Conference on Structural Safety and Reliability, New York, NY, USA, 2013, pp. 1025-1032. [online] Available at: https://www.researchgate.net/ publication/332028176

[14] Yang, Y., Li, C. "Performance of tuned tandem mass dampers for structures under the ground acceleration", Structural Control and Health Monitoring, 24(10), Article ID e1974, 2017. https://doi.org/10.1002/stc.1974

[15] Cao, L., Li, C. "Tuned tandem mass dampers-inerters with broadband high effectiveness for structures under white noise base excitations", Structural Control and Health Monitoring, 26(4), Article ID e2319, 2019. https://doi.org/10.1002/stc.2319

[16] Fahimi Farzam, M., Kaveh, A. "Optimum Design of Tuned Mass Dampers Using Colliding Bodies Optimization in Frequency Domain", Iranian Journal of Science and Technology - Transactions of Civil Engineering, 44(3), pp. 787-802, 2020. https://doi.org/10.1007/s40996-019-00296-6

[17] Salvi, J., Rizzi, E., Rustighi, E., Ferguson, N. S. "Optimum Tuning of Passive Tuned Mass Dampers for the Mitigation of Pulse-Like Responses", Journal of Vibration and Acoustics, 140(6), Article number: 061014, 2018. https://doi.org/10.1115/1.4040475

[18] Smith, M. C. "Synthesis of mechanical networks: The inerter", IEEE Transactions on Automatic Control, 47(10), pp. 1648-1662, 2002. https://doi.org/10.1109/TAC.2002.803532

[19] Ruiz, R., Taflanidis, A. A., Giaralis, A., Lopez-Garcia, D. "Riskinformed optimization of the tuned mass-damper-inerter (TMDI) for the seismic protection of multi-storey building structures", Engineering Structures, 177, pp. 836-850, 2018. https://doi.org/10.1016/j.engstruct.2018.08.074 
[20] Nigdeli, S. M., Bekdaş, G. "Optimum tuned mass damper design in frequency domain for structures", KSCE Journal of Civil Engineering, 21(3), pp. 912-922, 2017. https://doi.org/10.1007/s12205-016-0829-2

[21] Salvi, J., Rizzi, E. "Optimum tuning of Tuned Mass Dampers for frame structures under earthquake excitation", Structural Control and Health Monitoring, 22(4), pp. 707-725, 2014. https://doi.org/10.1002/stc.1710

[22] Bekdaş, G. Nigdeli, S. M. "Estimating optimum parameters of tuned mass dampers using harmony search", Engineering Structures, 33(9), pp. 2716-2723, 2011.

https://doi.org/10.1016/j.engstruct.2011.05.024

[23] Bekdaş, G., Nigdeli, S. M., Yang, X.-S. "A novel bat algorithm based optimum tuning of mass dampers for improving the seismic safety of structures", Engineering Structures, 159, pp. 89-98, 2018. https://doi.org/10.1016/j.engstruct.2017.12.037

[24] Kaveh, A., Mohammadi, S., Khadem Hosseini, O., Keyhani, A., Kalatjari, V. R. "Optimum parameters of tuned mass dampers for seismic applications using charged system search", Iranian Journal of Science and Technology - Transactions of Civil Engineering, 39(C1), pp. 21-40, 2015.

https://doi.org/10.22099/IJSTC.2015.2739

[25] Kaveh, A., Fahimi Farzam, M., Maroofiazar, R. "Comparing h2 and h $\infty$ algorithms for optimum design of tuned mass dampers under near-fault and far-fault earthquake motions", Periodica Polytechnica Civil Engineering, 64(3), pp. 828-844, 2020. https://doi.org/10.3311/PPci.16389

[26] Leung, A. Y. T., Zhang, H. "Particle swarm optimization of tuned mass dampers", Engineering Structures, 31(3), pp. 715-728, 2009. https://doi.org/10.1016/j.engstruct.2008.11.017

[27] Kennedy, J., Eberhart, R. "Particle swarm optimization", In: Proceeding of the IEEE International Conference on Neural Networks, Perth, WA, Australia, 1995, pp. 1942-1948. https://doi.org/10.1109/ICNN.1995.488968

[28] Kaveh, A. "Applications of metaheuristic optimization algorithms in civil engineering", Springer, Cham, Switzerland, 2016. https://doi.org/10.1007/978-3-319-48012-1
[29] Yang, F., Sedaghati, R., Esmailzadeh, E. "Vibration suppression of structures using tuned mass damper technology: A state-of-the-art review", Journal of Vibration and Control, 2021. https://doi.org/10.1177/1077546320984305

[30] Den Hartog, J. P. "Mechanical vibrations", Dover Publications, New York, NY, USA, 1985.

[31] Zuo, L., Nayfeh, S. A. "Optimization of the individual stiffness and damping parameters in multiple-tuned-mass-damper systems", Journal of Vibration and Acoustics, 127(1), pp. 77-83, 2005. https://doi.org/10.1115/1.1855929

[32] Lee, C.-L., Chen, Y.-T., Chung, L.-L., Wang, Y.-P. "Optimal design theories and applications of tuned mass dampers", Engineering Structures, 28(1), pp. 43-53, 2006. https://doi.org/10.1016/j.engstruct.2005.06.023

[33] Li, C., Zhu, B. "Estimating double tuned mass dampers for structures under ground acceleration using a novel optimum criterion", Journal of Sound and Vibration, 298(1-2), pp. 280-297, 2006. https://doi.org/10.1016/j.jsv.2006.05.018

[34] Hadi, M. N. S., Arfiadi, Y. "Optimum design of absorber for MDOF structures", Journal of Structural Engineering, 124(11), pp. 12721279, 1998. https://doi.org/10.1061/(asce)0733-9445(1998)124:11(1272)

[35] Febbo, M., Vera, S. A. "Optimization of a two degree of freedom system acting as a dynamic vibration absorber", Journal of Vibration and Acoustics, 130(1), Article number: 011013, 2008. https://doi.org/10.1115/1.2827368

[36] Spencer Jr., B. F., Christenson, R. E., Dyke, S. J. "Next generation benchmark control problem for seismically excited buildings", [pdf] In: Proceedings of the second world conference on structural control, Kyoto Japan, 1999, pp.1135-1360. Available at: http://sstl.cee. illinois.edu/benchmarks/bench2def/ngbench.pdf

[37] Kaveh, A., Fahimi Farzam, M., Hojat Jalali, H., Maroofiazar, R. "Robust optimum design of a tuned mass damper inerter", Acta Mechanica, 231(9), pp. 3871-3896, 2020. https://doi.org/10.1007/s00707-020-02720-9 